\title{
Estimating Change in Species Richness from Repeated Sampling of Incidence Data
}

\author{
Steen Magnussen (Corresponding Author) \\ Canadian Forest Service, Pacific Forestry Center \\ 506 West Burnside Road, Victoria BC, V8Z 1M5, Canada. \\ Tel: 1- 250 -363-0712Ｅ-mail: steen.magnussen@nrcan.gc.ca
}

Received: June 1, 2011 Accepted: June 10, 2011 doi:10.5296/jee.v2i1.697

\begin{abstract}
Forest tree species richness is an important indicator of sustainability. Forest monitoring allows stake-holders to track species richness over time. To test a hypothesis of whether an observed change in richness is significant or not, the analyst must choose a suitable estimator. Based on experience from comparative studies of potential estimators this study evaluates the performance of one design-based and three model-based estimators of change in species richness. The evaluation is done with Monte Carlo simulations of simple random sampling from four actual populations of forest tree species incidence data collected at two occasions from a fixed set of fixed-area forest inventory plots. The observed change in species richness (design-based) had the lowest root mean squared error, but was often more biased than estimates from the three model-based estimators. The bias issue and poor coverage of $95 \%$ confidence intervals dissuade the use of the design-based estimator (observed change). A newly developed urn-type estimator, easily adaptable to processing longitudinal data, was overall best in terms of bias and coverage.
\end{abstract}

Keywords: Forest monitoring, Forest survey, Change estimator, Forest tree species richness, Urn-model 


\section{Introduction}

The number of forest tree species - henceforth referred to as richness $(\mathrm{S})$ - in a landscape, region, or a country is an important indicator of biological diversity (Purvis \& Hector, 2000; Waldhardt, Simmering, \& Otte, 2004). Forest tree species richness may change over time due to the intrinsic dynamic nature of forest vegetation and its environment (Condit, Hubbell, \& Foster, 1996; Kienast, Brzeziecki, \& Wildi, 1996; Martin \& Bailey, 1999; Radeloff, Mladenoff, He, \& Boyce, 1999). Examples include biotic and abiotic disturbances (H. S. He, Mladenoff, \& Gustafson, 2002; Radeloff, et al., 1999), changes in forest management (Halpern \& Spies, 1995; Swindel, Conde, \& Smith, 1984), invasion (Chong, Reich, Kalkhan, \& Stohlgren, 2001), mortality and seedling establishment (Gavin, Beckage, \& Osborne, 2008). Since a given estimate of change in species richness can cover widely different realities - in terms of species turn-over and replacement rates - an accompanying indicator of species similarity between the species composition at the start and the end of a period between two sampling events is needed as well (Cao, Larsen, \& White, 2004; Sarkar \& Margules, 2002).

To answer key questions regarding sustainable forestry, one must have reliable estimates of the state and change in a broad suite of forest attributes (McDonald \& Lane, 2004). Required estimates are typically provided through sample-based forest monitoring programs designed to satisfy multiple purposes and requirements for accuracy (Foster, 2001; Magnussen, Smith, \& Uribe, 2007; Spencer \& Czaplewski, 1998). To test whether species richness has changed or not during a period of interest the analyst must choose a design-consistent estimator suited for estimation of both richness and change in richness.

For the purpose of estimating forest tree species richness - at a given point in time - from species incidence data obtained from a probability-sample with fixed-area forest survey plots (quadrats), the analyst now has a choice of estimators with anticipated good performances provided the sample size is adequate (Magnussen \& Boudewyn, 2008; Magnussen, Péllisier, He, \& Ramesh, 2006; Magnussen, Smith, Kleinn, \& Sun, 2010). The situation is different when it comes to estimation of change in richness since studies on the performance of estimators of temporal change in species richness have been lacking. This study aims to redress this situation.

Estimating forest tree species richness from a forest inventory (monitoring) sample is a complex challenge with important issues related to temporal changes in the sample frame (Lister \& Scott, 2009), sample size (Brose, Martinez, \& Williams, 2003; Cao, et al., 2004; Hortal, Borges, \& Gaspar, 2006), plot size (Brose, et al., 2003; Gimaret-Carpentier, Pelissier, Pascal, \& Houllier, 1998; Shen \& He, 2008), species identification (Archaux, 2009; Archaux et al., 2009), and choice of estimator (Mao \& Lindsay, 2007; Walther \& Morand, 1998). This study only deals with the last issue but fully recognizes that its importance depends critically on having satisfactory addressed all the other issues first.

On the assumption that an analyst has acquired sample data that warrant an estimation of species richness and its change over time, the choice of estimator becomes important because the performance of available estimators varies considerably within a single application and 
among applications to samples from different populations (Magnussen \& Boudewyn, 2008; Walther \& Morand, 1998; Yasuhiro, Hirofumi, \& Kihachiro, 2004).

Temporal changes in forest tree species richness can be estimated as the difference between two point estimates of richness. However, when data come from a monitoring program, with repeat observations on a fixed set of survey plots, the estimator of variance should allow for the expected temporal covariance of species incidence. For long-lived, sessile organisms like forest tree species, the covariance is expected to be positive, at least when the time interval between the dates of the repeated sampling is relatively short compared to the expected lifespan in the surveyed population. A positive covariance lowers the variance of a difference estimated from paired observations (Lophaven, Carstensen, \& Rootzen, 2004).

This study details - by examples with actual forest tree species incidence data collected at two points in time - the performance of one design-based and three model-based estimators of temporal change in species richness when data come from a repeated survey of a fixed number of sample plots in a finite area population of forest tree species. The model-based estimators achieved the overall best performance (bias and root mean squared errors) for estimation of species richness in two extensive comparative studies with forest tree species incidence data from low-intensity forest sampling (Magnussen, 2011; Magnussen, et al., 2010). It is recognized that other estimators of richness may outperform the three chosen model-based estimators when sampling is intensified to impractical levels.

The design-based estimator of temporal change in forest tree species richness $\left(\Delta S_{O}\right)$ is the difference between the number of distinct species in the last and first sample. With practically relevant sample sizes, the observed species richness $\left(S_{O}\right)$ in a probability sample is typically a poor estimator of the actual species richness (Chiarucci, Enright, Perry, \& Miller, 2003; Magnussen \& Boudewyn, 2008; Wei et al., 2010). However, if the bias in the observed richness remains relatively constant during the period between two survey samples, the observed change in richness may become an attractive (design-based) estimator of actual change in richness.

The first $\left(\Delta S_{U R N}\right)$ and second $\left(\Delta S_{H T}\right)$ of the three model-based estimators have been proposed by Magnussen et al. (2010) and Magnussen (2011), respectively. They are both easily modified to cope with repeat observations of species incidence data. The third model-based estimator $\left(\Delta S_{H W}\right)$ is the difference between a time two and a time one estimate of species richness obtained with the estimator proposed by Hwang and Shen (2010). This estimator cannot directly accommodate temporal covariances in species incidence data. To capture a temporal covariance in incidence data it becomes necessary to embed the estimation of change in richness within a modified bootstrap resampling scheme (Magnussen, 2009; Magnussen \& McRoberts, 2011).

As an aide to the interpretation of the presented estimates of change in species richness I also 
provide summaries of Jaccard's and Sørensen`s indices of similarity of species composition between the first and last sample (Fewster \& Buckland, 2001).

\section{Material and Methods}

\subsection{Population and sampling design}

To estimate the temporal change in species richness in a finite area population of forest tree species, a population is sampled on two occasions $(t=1,2)$ by simple random sampling without replacement (wor) - of $n$ fixed-area plots. The population is tessellated into $\mathrm{N}$ fixed-area plots, and the $n$ surveyed plots are the same on both occasions. There are St distinct forest tree species in the population at time $t$. Let $S_{\mathrm{O} 1}$ and $S_{\mathrm{O} 2}$ denote the observed number of distinct species in the $n$ sampled plots at time one and two, respectively. The (longitudinal) sample data consist of indicator $(0,1)$ variables $\delta_{t i j}$ of species plot occurrence (incidence) where $\delta_{t i j}=1$ if species $i\left(i=1, \ldots . \max \left(S_{O 1}, S_{O 2}\right)\right)$ is observed in $\operatorname{plot} j(j=1, \ldots$, $n$ ) at time $t(t=1,2)$, and $\delta_{t i j}=0$ otherwise. A species that occurs in only one sample plot at time $t$ is called a time $t$ singleton species (SI). For a given species richness estimator (EST, see below) let $\tilde{S}_{E S T 1}$, and $\tilde{S}_{E S T 2}$, denote the estimates of forest tree species richness at time 1

and time 2, and let and $\Delta \tilde{S}_{E S T}$ denote the estimator of change $\left(\Delta \tilde{S}_{E S T}=\tilde{S}_{E S T 2}-\tilde{S}_{E S T 1}\right)$. An estimate of the sampling variance for the estimate of change is required. A nominal $95 \%$ confidence interval for the true (but unknown) change in forest tree species richness is computed from the estimates of change and sampling variance.

\subsection{Observed change in species richness}

The change in the observed number of distinct species in the sample at time one and two is used here as a direct estimator of change in species richness $\Delta \tilde{S}_{O}=S_{O 2}-S_{O 1}$. With practical sample sizes, $S_{O t}$ is typically a poor estimator of species richness (Walther \& Morand, 1998), however, if bias is approximately constant during the period in question, the estimator $\Delta \tilde{S}_{O}$ might perform well (i.e., approximately unbiased).

The following variance estimator for the observed number of species at time $t$ is proposed.

(1) $\operatorname{var}\left(S_{O t}\right)=\left(\sum_{i}^{S_{O t}} \sum_{j}^{S_{O t}} 1-\frac{\text { 旗, } \pi_{t, j}}{\hat{\pi}_{t, i j}}\right)\left(\sum_{i}^{S_{O t}} 1-\text { 许, }\right)^{-1} \times \sum_{i=1}^{S_{O t}} \pi_{t, i}\left(1-\pi_{t, i}\right)$

where the first term is a variance-inflation term (due to species covariances), and the last term is the sum of binomial variances of species presence (assuming independence of species occurrence). The variance of the difference $S_{O 2}-S_{O 1}$ was computed as 
(2)

$$
\begin{aligned}
& \tilde{\operatorname{var}}\left(\Delta \tilde{S}_{O}\right)= \\
& \tilde{\operatorname{var}}\left(S_{O 2}\right)+\tilde{\operatorname{var}}\left(S_{O 1}\right)-2 \hat{\rho}\left(S_{O 1}, S_{O 2}\right) \sqrt{\tilde{\operatorname{var}}\left(S_{O 2}\right) \tilde{\operatorname{var}}\left(S_{O 1}\right)}
\end{aligned}
$$

where the correlation coefficient $\hat{\rho}\left(S_{O_{1}}, S_{O_{2}}\right)$ was computed from 1500 paired bootstrap samples of size $n$ taken (with replacement) from the combined $t=1$ and $t=2$ sample.

\subsection{A HT-type estimator of change in species richness}

Magnussen (2011) proposed the following sample-based HT-type estimator of species richness

(3) $\tilde{S}_{H T, t}==\sum_{i=1}^{S_{O t}}$ 谁, $\pi_{t, i}{ }^{-1}=\sum_{i=1}^{S_{O t}}\left(1+B I A S_{t, i}\right) \pi_{t, i}{ }^{-1}$

where $\hat{\pi}_{t, i}$ is a sample-based estimate of the inclusion probability for the $i^{\text {th }}$ species, $\hat{y}_{t, i}$ is a model-assisted estimate of the number of species with inclusion probability $\hat{\pi}_{t, i}$ and $B I A S_{t, i}$ is an estimate of the number of missed species with an inclusion probability of $\hat{\pi}_{t, i}$. Computational details of $\hat{\pi}_{t, i}, \hat{y}_{t, i}$, and $B I A S_{t, i}$ are in Magnussen (2011).

The HT-type estimator of $S_{2}-S_{1}$ can be written as

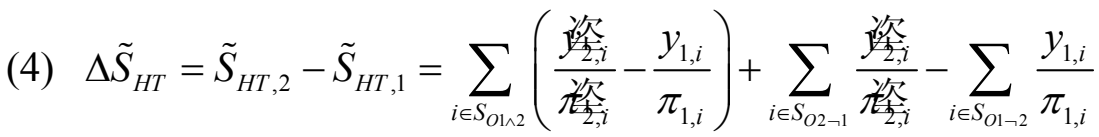

where the right-hand-side of (4) facilitates a formulation of a variance estimator (below). In (4) the estimated change is: 1) the net change as estimated from species seen in both samples $\left(S_{O 1 \wedge 2}\right)$ plus 2 ) the estimated number of new time two species (as estimated from the species seen only in the second sample $\left(S_{O 2 \neg 1}\right)$ minus 3$)$ the estimated number of species lost as derived from the species seen only on the first sample $\left(S_{O_{1 \neg 2}}\right)$.

In place of a slightly liberal (10\%-15\%) variance estimator used in Magnussen (2011) a more conservative estimator of variance is proposed here for $\tilde{S}_{H T t}$ (Thompson, 1992, p 46) 
(5) $\tilde{\operatorname{var}}\left(\tilde{S}_{H T, t}\right)=\operatorname{var}\left(\frac{\hat{y}_{t, i}}{\hat{\pi}_{t, i}}\right) \tilde{S}_{H T, t}+\left(\frac{\tilde{S}_{H T, t}}{S_{O t}}\right) \tilde{\operatorname{var}}\left(S_{O t}\right)$

Taken together, the estimators in (3) - (5) suggest the following variance estimator for $\Delta \tilde{S}_{H T}$

(6)

$$
\begin{aligned}
\tilde{\operatorname{var}}\left(\Delta \tilde{S}_{H T}\right)= & \operatorname{var}\left(\left(\frac{\text { 资, }}{\text { 资, }}-\frac{y_{1, i}}{\pi_{1, i}}\right) \mid i \in S_{O 1 \wedge 2}\right) \tilde{S}_{H T}\left(S_{O 1 \wedge 2}\right) \\
& +\operatorname{var}\left(\frac{\hat{y}_{2, i}}{\hat{\pi}_{2, i}} \mid i \in S_{O 2 \neg 1}\right) \tilde{S}_{H T}\left(S_{O 2 \neg 1}\right) \\
& +\operatorname{var}\left(\frac{\hat{y}_{1, i}}{\hat{\pi}_{1, i}} \mid i \in S_{O 1 \neg 2}\right) \tilde{S}_{H T}\left(S_{O 1 \neg 2}\right) \\
& +\sum_{t=1}^{2} \sum_{t^{\prime}=1}^{2} \hat{\rho}\left(S_{O t}, S_{O t^{\prime}}\right) \sqrt{\frac{\tilde{S}_{H T t}}{S_{O t}} \tilde{\operatorname{var}}\left(S_{O t}\right)} \sqrt{\frac{\tilde{S}_{H T t^{\prime}}}{S_{O t^{\prime}}} \tilde{\operatorname{var}}\left(S_{O t^{\prime}}\right)}
\end{aligned}
$$

where $\tilde{S}_{H T}(A)$ denotes a HT-type estimator of richness applied to a subset $A$ of the observed species. A positive correlation between $S_{O 1}$ and $S_{O 2}$ will increase the variance of an estimate of change in species richness.

\subsection{An urn-model estimator of change in species richness}

Magnussen et al. (2010) proposed an urn-model for predicting species richness $\left(S_{U R N}\right)$ from a probability sample of species incidence data. With minor modifications it can predict $S_{2}-S_{1}$. The urn-model works by making one-step-ahead predictions of the discovery of new species in the $N-n$ plots not included in the sample. It is called an urn-model because it employs an urn filled with labelled balls, each representing a plot with a known or predicted number of time $t$ singletons $\left(n S I_{t}, t=1,2\right)$. A random draw of a ball from the urn triggers a plot-level prediction of a new discovery at time $t(1,2)$. After a prediction is made, the drawn ball and one additional ball are returned to the urn. This urn-scheme is continued until a prediction has been made for all $N-n$ plots not in the sample or until the maximum time-specific probability of discovering new species is zero. Only the draw of a ball representing a plot with at least one SI can trigger the discovery of a new species. A step-by-step description of the urn-model is in Table 1.

The urn-scheme in Table 1 was repeated 400 times to get a resampling distribution of the predicted change in species richness $\left(\tilde{S}_{U R N 2}-\tilde{S}_{U R N 1}\right)$. The mean and variance of the 400 urn-replications serve as estimators of $\Delta \tilde{S}_{U R N}$, and $\tilde{\operatorname{var}}\left(\Delta \tilde{S}_{U R N}\right)$, respectively. Quantiles $(0.025$ 
and 0.975 ) in the urn replications of $\tilde{S}_{U R N 2}-\tilde{S}_{U R N 1}$ were used as the upper and the lower limit of a $95 \%$ confidence interval for $S_{2}-S_{1}$.

Table 1. Algorithm for a single urn-prediction of species richness at time $t=1$ and $t=2$ from a probability sample of $n$ fixed-area survey plots.

\begin{tabular}{|c|c|}
\hline Step & Description \\
\hline 0 & $\begin{array}{l}\text { Place } n \text { balls - each representing a survey plot - in an urn. On each ball is written the } \\
\text { number of singleton species in the corresponding plot at the times of the repeated survey } \\
\left(n S I_{t, i}, t=1,2, i=1, \ldots, n\right) ; \text { set } n_{U R N}=n \text {. }\end{array}$ \\
\hline 1 & $\begin{array}{l}\text { Set urn species counters equal to the observed species richness in the sample at times } t=1 \\
\text { and } t=2 \text { i.e. } S_{U R N I}=S_{O I} \text {, and } S_{U R N, 2}=S_{O 2} \text {. }\end{array}$ \\
\hline \multirow[t]{2}{*}{2} & Draw at random a ball from the urn with index, say, $i^{*}, i^{*}=1, \ldots, n_{U R N}$. \\
\hline & 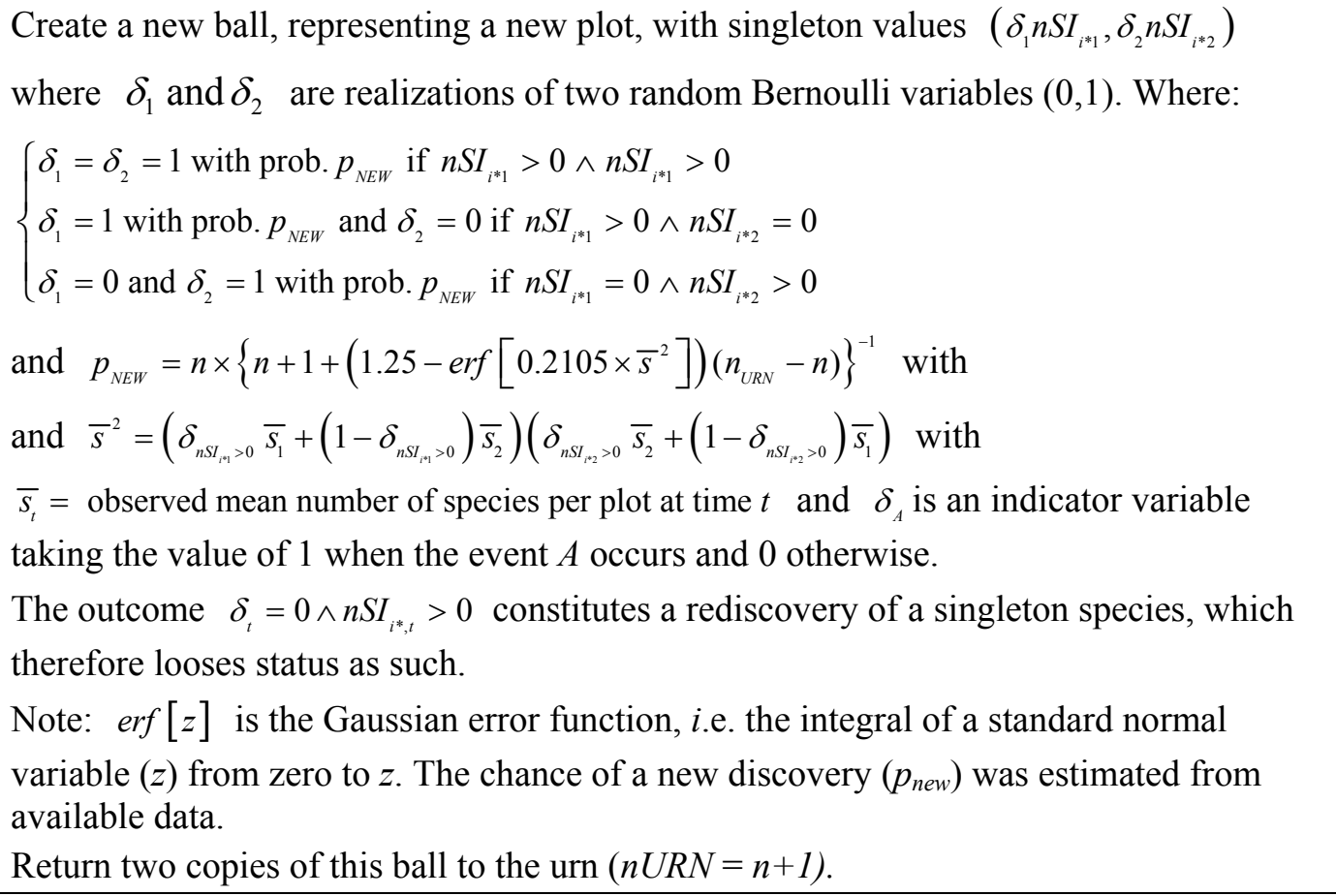 \\
\hline 3 & Update species counters: $S_{U R N 1}=S_{U R N 1}+\delta_{1}$, and $S_{U R N 2}=S_{U R N 2}+\delta_{2}$. \\
\hline 4 & If $n_{U R N}<N \wedge \max \left(\sum_{i=1}^{n_{w n}} n S I_{t, t}, \sum_{i=1}^{n_{m i n}} n S I_{2, t}\right)>0$ GOTO 2 \\
\hline 5 & $\begin{array}{l}S_{U R N 1} \text { and } S_{U R N 2} \text { are single replication predictions of richness at time } t=1,2 . \\
\text { Steps } 0-5 \text { are repeated } M \text { times to generate a resampling distribution of } S_{U R N 1} \text { and } S_{U R N 2} \text {. }\end{array}$ \\
\hline
\end{tabular}

\subsection{Hwang's estimator of change in species richness}

Hwang and Shen (2010) proposed a generalized jackknife estimator (HW) of species richness

(7) $\tilde{S}_{H W, t}=S_{O t}+\hat{f}_{t, 0}, t=1,2$ 
where $\hat{f}_{t, 0}$ is an estimate of the 'unseen' species at time $t$, which, in turn, is estimated from $\hat{g}_{t}(0) f_{t, 1} n^{-1}$ with $f_{t, k}$ equal to the number of species occurring in $k$ sample plots at time $t$.

The function $g_{t}(k)=(n-k) E\left[f_{t, k}\right]\left\{(k+1) E\left[f_{t, k+1}\right]\right\}^{-1}$ is approximated by an exponential regression model and estimated from the data via constrained nonlinear least squares regression (see Hwang and Shen for details); $\hat{g}_{t}(0)$ is then obtained by extrapolation. The HW estimator of species richness change becomes

(8) $\Delta \tilde{S}_{H W}=S_{O 2}+\frac{\text { 资 }}{2,0}-S_{O 1}-f_{1,0}$

with variance estimator

(9) $\tilde{\operatorname{var}}\left(\Delta \tilde{S}_{H W}\right)=\tilde{\operatorname{var}}\left(\tilde{S}_{H W 2}\right)+\tilde{\operatorname{var}}\left(\tilde{S}_{H W 1}\right)-2 \tilde{\operatorname{cov}}\left(\tilde{S}_{H W 2}, \tilde{S}_{H W 1}\right)$

Hwang and Shen recommend a bootstrap procedure to compute the variances of $\tilde{S}_{H W t}$. Since no direct estimation of the covariance in (9) is possible, a modified bootstrap procedure (Magnussen \& McRoberts, 2011) with $B=100$ replications was used to generate estimates of the needed variances and covariances. The B bootstrap estimates of $\Delta \tilde{S}_{H W}$ were also used to obtain bias-corrected (accelerated) 95\% confidence intervals (Efron \& Tibshirani, 1993, p 184).

\subsection{Case studies}

Forest tree species data collected at two points in time from one stem-mapped forested area (BCI), and three USA state-wide forest inventories (GA, MI, and MN) are used to demonstrate estimation of temporal change in species richness in finite populations from repeated wor sampling of $n$ fixed-area plots. Data details are below. The net change in forest tree species richness in these data sets was modest $(-2$ to +5 , see Table 2$)$. In order to demonstrate the performance of the proposed estimators in presence of an important loss of species richness (approximately 5\% to 10\%) between time one and time two, the data were manipulated to this end.

A given target loss in species richness $\left(S_{2}-S_{1}\right)$ was achieved by the following manipulations of the species incidence matrix: $i$ ) elimination of some of the species seen only at time two; if the target is not reached by the manipulation in $i$ ) then additional changes were generated by $i$ ) switching some species seen only at time two to species seen only at time one; if the target is still not met then the variance was met by iii) changing time two incidence to zero for a number of species found both at time one and time two. 
BCI: This consists of a 50-ha Smithsonian research area on the Barro Colorado Island in the Panama Canal (Condit et al., 1998; F. He \& Hubbell, 2003). The area holds a rich, old-growth, wet tropical forest dominated by Leguminosae spp. and Bombaceae spp. (Condit \& Hubbell, 1998; Hubbell et al., 1999). Data (tree location and species name of live trees) from the first (1981-1982) and sixth (2005) census are used here. The $1000 \mathrm{~m} \times 500 \mathrm{~m}$ area was tessellated into plots of size $10 \mathrm{~m} \times 10 \mathrm{~m}$. A summary is in Table 2 .

GA, MI, and MN: Data from these three populations came from the USDA Forest Service, Forest Inventory and Analysis (FIA) program. The data represent state-wide forest inventories from Georgia (GA), Michigan (MI), and Minnesota (MN). The FIA sampling frame and design is described by Bechthold and Patterson (Bechtold \& Patterson, 2005). All trees in a FIA plot with a stem diameter of $12.7 \mathrm{~cm}$ or larger at a reference level of $1.37 \mathrm{~m}$ above ground were counted and identified to species. Time one data were from plots measured in 2001-2004 and time two data were from the same plots measured again in 2005-2008. The time between two surveys of the same plot was nominally 5 years. Only plots with a forest cover of at least $50 \%$ at time one are used here. A summary of the GA, MI, and MN data is in Table 2.

Table 2. Data summary

\begin{tabular}{|l|r|r|r|r|}
\hline Attribute & BCI & \multicolumn{1}{|c|}{ GA } & \multicolumn{1}{c|}{ MI } & \multicolumn{1}{c|}{ MN } \\
\hline Population size (plots), $N=$ & 5000 & 3213 & 5851 & 4117 \\
\hline Plot size $\left(\mathrm{m}^{2}\right)$ & 100 & 671 & 671 & 671 \\
\hline Tree density at $t=1$ (stems $\times$ ha-1) & 4707 & 93 & 82 & 70 \\
\hline Tree density at $t=2$ (stems $\times$ ha-1) & 5021 & 96 & 85 & 71 \\
\hline Species richness $(S)$ at $t=1$ & 306 & 142 & 97 & 68 \\
\hline Species richness $(S)$ at $t=2$ & 308 & 143 & 102 & 66 \\
\hline Species present at $t=1$ and $t=2$ & 296 & 132 & 92 & 61 \\
\hline Mean number of species per plot $(t=1)$ & 23.0 & 6.2 & 5.5 & 4.7 \\
\hline Mean number of species per plot $(t=2)$ & 23.9 & 6.5 & 5.7 & 4.8 \\
\hline Quartiles of species relative plot occurrence $\times 10^{3}(t=1)$ & 2.6 & 1.6 & 1.0 & 1.7 \\
\hline Quartiles species relative plot occurrence $\times 10^{3}(t=2)$ & 2.6 & 1.2 & 0.5 & 1.7 \\
\hline Quartiles of correlation $(t=1, t=2)$ of species plot occurrence & 0.41 & 0.71 & 0.71 & 0.68 \\
\hline
\end{tabular}

\subsection{Indices of temporal similarity in species composition}

Jaccard's (Jaccard, 1901) and Sørensen's (Sørensen, 1957) indices of species similarity were estimated from the simulated samples to gauge the rate of species turn-over between the two sampling occasions at time one and two. Jaccard's index was computed as 


\section{Macrothink}

(10) $\hat{J}_{1,2}=\frac{\left|S_{O 1} \cap S_{O 2}\right|}{\left|S_{O 1} \cup S_{O 2}\right|}$

and Sørensen's as

(11) $\hat{Q} S_{1,2}=\frac{2\left|S_{O 1} \cup S_{O 2}\right|}{S_{O 1}+S_{O 2}}$

\subsection{Performance of estimators}

The performance of the four estimators of change $\Delta \tilde{S}_{O}, \Delta \tilde{S}_{H T}, \Delta \tilde{S}_{U R N}$, and $\Delta \tilde{S}_{H W}$ was assessed in Monte Carlo (MC) simulations of simple random sampling without replacement from the four study populations. Sample sizes were fixed at $n=80,150,200$, and 300. Each combination of sample size, population, and estimator was repeated $M=2000$ times. The choice of $M$ ensures an MC error of less than 0.3 in $S_{O}$.

Bias of an estimator of change in species richness is estimated as the difference between the average of $M \mathrm{MC}$ estimates and the corresponding value of the actual change. Root mean squared errors (RMSE) are estimated as the square root of the mean squared difference between an estimate and the corresponding true value. Coverage of computed 95\% confidence intervals was estimated as the proportion of $M$ intervals that included the true value of change.

\section{Results}

$\underline{B C I}$. Jaccard's index of similarity suggested a relatively high species turn-over rate of approximately $17 \%$ between the two occasions of observation (Table 3). Sørensen's index, which is strongly correlated with Jaccard's index $\left(\hat{\rho}_{J, Q S} \approx 0.96\right)$, suggests a fairly strong similarity of 0.91 (Table 3). Similarity indices were almost identical across scenarios of change.

The least biased estimates of actual change in species richness between the first and sixth census were achieved with the HT-type estimator (Table 4); the most biased estimates came from the HW estimator. An increase in sample size lowered the bias of all estimators. RMSEs were - by far - the smallest for $\Delta S_{O}$ and largest for HW. RMSEs of $\Delta S_{O}$ were only approximately $33 \%-50 \%$ of the RMSEs of the HT estimator, which had the second lowest RMSEs. Computed 95\% confidence intervals for HT estimates of change achieved coverages close to the nominal value (Table 4).

When the change in species richness was manipulated to losses of 10 and 19 tree species, the least biased results were, most often, obtained with the HW estimator (Table 4), and the most biased with the observed change $\left(\Delta S_{O}\right)$. For a sample size of 300 the bias of URN was similar to that of HW. In terms of RMSE it is again $\Delta S_{O}$ that is most attractive. It has an average RMSE approximately 44\% smaller than the RMSE of HW estimates of change. 
However, computed confidence intervals for $\Delta S_{O}$ estimates of change had very poor coverage while those of the HW estimator achieved coverages in the $0.92-0.99$ range.

$\underline{G A}$. Jaccard's index of similarity suggested a species turn-over rate of approximately $15 \%$ (Table 3) while Sørensen's index suggests a relatively strong stability in species composition (Table 3). As in BCI the two indices appear unaffected by the magnitude of change in species richness.

Table 3. Jaccard's $\left(J_{1,2}\right)$ and Sørensen's $\left(Q S_{1,2}\right)$ indices of species similarities at time one and two. All table entries are the mean of $2000 \mathrm{MC}$ replications with sample size $n=80$. Monte-Carlo estimates of sampling error are in parentheses.

\begin{tabular}{|l|r|c|c|}
\hline Site & \multicolumn{1}{|c|}{$S_{I} S_{2}$} & $J_{l, 2}$ & $Q S_{l, 2}$ \\
\hline BCI & 2 & $0.83(0.02)$ & $0.91(0.01)$ \\
BCI & -10 & $0.83(0.02)$ & $0.91(0.01)$ \\
BCI & -19 & $0.83(0.02)$ & $0.91(0.01)$ \\
\hline GA & 1 & $0.85(0.04)$ & $0.92(0.02)$ \\
GA & -7 & $0.86(0.04)$ & $0.92(0.02)$ \\
GA & -14 & $0.85(0.04)$ & $0.92(0.02)$ \\
\hline MI & 5 & $0.89(0.04)$ & $0.94(0.02)$ \\
MI & -5 & $0.90(0.04)$ & $0.94(0.02)$ \\
MI & -10 & $0.90(0.04)$ & $0.95(0.02)$ \\
\hline MN & -2 & $0.88(0.04)$ & $0.94(0.02)$ \\
MN & -5 & $0.89(0.04)$ & $0.94(0.02)$ \\
MN & -10 & $0.89(0.04)$ & $0.94(0.02)$ \\
\hline
\end{tabular}

The actual increase of one species was estimated with the least amount of bias by the observed change in species richness (Table 5). The HT estimator had the second lowest bias for $n<300$; at $n=300$ the second best result in terms of bias came from the HW estimator. With a manipulated loss of seven species, the URN estimator was the least biased for $n \leq 150$. For larger $n$ the HT estimator was the least biased. When the loss was set to 14 species, the URN estimator was the least biased while the observed change was the most biased. The ranking of RMSEs was nearly identical to the RMSE rankings noted for BCI. Computed confidence intervals for HT and URN estimates were conservative (coverage $>0.95$ ) for the first two levels of change in species richness, but generally liberal (coverage $<0.95$ ) when the change in richness was set to -14 species. Confidence interval for the observed change had poor coverage when the manipulated changes were equal to losses of seven and 14 species.

Table 4. Estimates of change in tree species richness in Barro Colorado Island plot (BCI). RMSE and coverage of $95 \%$ confidence intervals are in parentheses (RMSE, coverage). 


\begin{tabular}{|c|c|c|c|c|c|}
\hline$S_{2}-S_{1}$ & EST & $n=80$ & $n=150$ & $n=200$ & $n=300$ \\
\hline \multirow[t]{4}{*}{2} & $\Delta \tilde{S}_{O}$ & $-1.1(6.8,0.86)$ & $-0.6(6.1,0.92)$ & $-0.3(5.8,0.94)$ & $0.0(5.3,0.97)$ \\
\hline & $\Delta \tilde{S}_{H T}$ & $1.1(18.1,0.95)$ & $1.2(15.8,0.97)$ & $1.5(15.3,0.96)$ & $1.8(13.5,0.95)$ \\
\hline & $\Delta \tilde{S}_{U R N}$ & $4.9(39.3,0.99)$ & $4.6(36.7,0.98)$ & $3.4(31.4,0.99)$ & $2.8(29.2,0.98)$ \\
\hline & $\Delta \tilde{S}_{H W}$ & $-6.9(40.1,0.68)$ & $-5.7(38.1,0.67)$ & $-0.8(36.4,0.72)$ & $-0.8(35.5,0.72)$ \\
\hline \multirow[t]{4}{*}{-10} & $\Delta \tilde{S}_{O}$ & $-1.7(14.6,0.33)$ & $-1.9(14.4,0.34)$ & $-2.1(13.9,0.37)$ & $-2.6(13.3,0.41)$ \\
\hline & $\Delta \tilde{S}_{H T}$ & $-1.7(22.7,0.84)$ & $-2.3(22.7,0.83)$ & $-3.0(19.3,0.87)$ & $-4.9(17.6,0.87)$ \\
\hline & $\Delta \tilde{S}_{U R N}$ & $-0.2(41.6,0.98)$ & $-4.7(32.7,0.99)$ & $-5.9(34.0,0.98)$ & $-8.5(30.8,0.96)$ \\
\hline & $\Delta \tilde{S}_{H W}$ & $-3.1(56.5,0.98)$ & $-12.9(47.3,0.99)$ & $-9.9(41.1,0.99)$ & $-11.3(37.9,0.98)$ \\
\hline \multirow[t]{4}{*}{-19} & $\Delta \tilde{S}_{O}$ & $-3.5(28.1,0.00)$ & $-4.9(26.6,0.00)$ & $-5.1(26.5,0.00)$ & $-6.4(25.1,0.00)$ \\
\hline & $\Delta \tilde{S}_{H T}$ & $-5.5(31.4,0.68)$ & $-10.0(26.4,0.75)$ & $-9.9(26.0,0.71)$ & $-13.2(23.0,0.75)$ \\
\hline & $\Delta \tilde{S}_{U R N}$ & $-8.6(45.4,0.95)$ & $-16.5(36.3,0.91)$ & $-15.5(34.9,0.88)$ & $-21.5(30.9,0.90)$ \\
\hline & $\Delta \tilde{S}_{H W}$ & $-12.7(59.2,0.97)$ & $-21.3(48.2,0.92)$ & $-23.4(42.1,0.92)$ & $-21.3(38.3,0.95)$ \\
\hline
\end{tabular}

$\underline{M I}$. Indices of species similarity were, as expected, higher than in sites with greater species richness (BCI and GA). Jaccard's index suggests a species turn-over rate of approximately 10\% (Table 3) while Sørensen's index suggests a fairly strong stability in species composition (Table 3). As before the two indices appear unaffected by the magnitude of change in species richness.

The least biased estimate of the actual increase of five species came from the observed richness when the sample size was 80 . For other sample sizes, the least biased estimator was HW (Table 6). When the loss of species was set to five, it was the URN estimator that produced the least biased estimates for $n \leq 200$, and then HT for $n=300$. With a loss of 10 species it was HW that generated the least biased estimates. At $n=80$ the bias of HW and 
URN was equal at 8.2. Trends in RMSEs and coverage of computed confidence intervals were, by and large, similar to those reported for BCI and GA.

Table 5. Estimates of change in tree species richness in Georgia (GA). RMSE and coverage of $95 \%$ confidence intervals are in parentheses (RMSE, coverage).

\begin{tabular}{|c|c|c|c|c|c|}
\hline$S_{2}-S_{1}$ & EST & $n=80$ & $n=150$ & $n=200$ & $n=300$ \\
\hline \multirow[t]{4}{*}{1} & $\Delta \tilde{S}_{O}$ & $-0.1(3.6,0.89)$ & $-0.0(3.4,0.90)$ & $0.5(3.2,0.91)$ & $0.6(3.0,0.94)$ \\
\hline & $\Delta \tilde{S}_{H T}$ & $-1.4(10.6,0.98)$ & $-0.7(10.4,0.98)$ & $-0.6(9.8,0.98)$ & $-0.1(9.3,0.98)$ \\
\hline & $\Delta \tilde{S}_{U R N}$ & $-2.6(20.6,0.98)$ & $-2.3(20.4,0.97)$ & $-2.0(19.7,0.98)$ & $-0.3(17.7,0.99)$ \\
\hline & $\Delta \tilde{S}_{H W}$ & $9.0(36.5,0.63)$ & $7.4(31.2,0.60)$ & $4.2(30.1,0.68)$ & $1.8(26.0,0.68)$ \\
\hline \multirow[t]{4}{*}{-7} & $\Delta \tilde{S}_{O}$ & $-0.3(7.3,0.23)$ & $-1.1(6.6,0.45)$ & $-2.0(5.9,0.63)$ & $-2.7(5.4,0.76)$ \\
\hline & $\Delta \tilde{S}_{H T}$ & $-3.0(10.2,0.97)$ & $-4.2(9.9,0.98)$ & $-5.9(9.8,0.97)$ & $-6.0(9.3,0.97)$ \\
\hline & $\Delta \tilde{S}_{U R N}$ & $-7.0(19.8,0.97)$ & $-7.2(19.4,0.98)$ & $-9.4(19.4,0.96)$ & $-9.2(16.8,0.96)$ \\
\hline & $\Delta \tilde{S}_{H W}$ & $-0.3(35.4,0.62)$ & $-0.8(31.3,0.62)$ & $-2.7(29.1,0.70)$ & $-4.4(25.9,0.72)$ \\
\hline \multirow[t]{4}{*}{-14} & $\Delta \tilde{S}_{O}$ & $-0.9(13.4,0.01)$ & $-2.2(12.2,0.03)$ & $-3.3(11.2,0.11)$ & $-4.5(10.0,0.23)$ \\
\hline & $\Delta \tilde{S}_{H T}$ & $-4.8(13.1,0.89)$ & $-7.2(11.8,0.93)$ & $-9.1(11.3,0.93)$ & $-10.1(9.9,0.96)$ \\
\hline & $\Delta \tilde{S}_{U R N}$ & $-10.0(20.6,0.93)$ & $-12.6(10.0,0.89)$ & $-14.4(19.3,0.88)$ & $-14.9(10.0,0.85)$ \\
\hline & $\Delta \tilde{S}_{H W}$ & $-4.2(34.3,0.61)$ & $-7.1(30.6,0.84)$ & $-7.3(28.5,0.86)$ & $-9.7(26.1,0.84)$ \\
\hline
\end{tabular}

$\underline{M N}$. Indices of species similarity were very similar to those reported for MI.

The URN estimator was, for $n>80$, the least biased for estimating the actual loss of two species (Table 7). With $n=80$ the least biased estimate of change came from the HT estimator. The most biased estimator was HW. When the change was manipulated to a loss of five species it was URN that produced the least biased estimates. Yet, with a loss of 10 species and sample sizes larger than 80, the HW estimator was best in terms of bias. For $n=$ 80 the least biased estimate came with the URN estimator. RMSEs were again the smallest for the observed change $\left(\Delta S_{O}\right)$ and approximately two to five times larger for the HW 
estimator. RMSEs of the HW estimator were typically more than twice as large as the RMSEs of the HT estimator. RMSEs of the URN estimator were, as a rule, intermediate between those of the HT-type and the HW estimators. Computed confidence intervals for the URN estimates achieved, with one exception (change $=-10$ species, $n=300$ ) a coverage in the range from 0.91 to 0.97 .

Table 6. Estimates of change in tree species richness in Michigan (MI). RMSE and coverage of $95 \%$ confidence intervals are in parentheses (RMSE, coverage).

\begin{tabular}{|c|c|c|c|c|c|}
\hline$S_{2}-S_{1}$ & EST & $n=80$ & $n=150$ & $n=200$ & $n=300$ \\
\hline \multirow[t]{4}{*}{5} & $\Delta \tilde{S}_{O}$ & $1.2(4.5,0.38)$ & $1.4(4.2,0.43)$ & $1.4(4.2,0.46)$ & $1.4(4.2,0.50)$ \\
\hline & $\Delta \tilde{S}_{H T}$ & $0.4(8.6,0.86)$ & $1.5(8.4,0.93)$ & $1.6(7.7,0.93)$ & $2.2(7.4,0.96)$ \\
\hline & $\Delta \tilde{S}_{U R N}$ & $-0.9(16.6,0.94)$ & $0.3(16.2,0.96)$ & $1.1(15.2,0.92)$ & $3.7(15.1,0.92)$ \\
\hline & $\Delta \tilde{S}_{H W}$ & $11.1(28.3,0.63)$ & $6.3(25.6,0.66)$ & $5.8(21.4,0.74)$ & $3.7(11.4,0.74)$ \\
\hline \multirow[t]{4}{*}{-5} & $\Delta \tilde{S}_{O}$ & $0.5(5.9,0.10)$ & $0.2(5.6,0.19)$ & $-0.1(5.4,0.25)$ & $-0.7(4.8,0.36)$ \\
\hline & $\Delta \tilde{S}_{H T}$ & $0.0(8.2,0.89)$ & $-1.4(7.5,0.94)$ & $-2.1(7.7,0.91)$ & $-3.6(7.2,0.92)$ \\
\hline & $\Delta \tilde{S}_{U R N}$ & $-1.3(15.2,0.93)$ & $-3.9(14.5,0.95)$ & $-4.7(14.8,0.96)$ & $-7.7(15.1,0.94)$ \\
\hline & $\Delta \tilde{S}_{H W}$ & $-17.8(28.0,0.70)$ & $-13.6(23.9,0.67)$ & $-11.5(19.2,0.74)$ & $-1.0(21.0,0.71)$ \\
\hline \multirow[t]{4}{*}{-10} & $\Delta \tilde{S}_{O}$ & $0.5(11.6,0.00)$ & $0.1(10.6,0.00)$ & $-0.3(10.0,0.00)$ & $-1.0(9.3,0.03)$ \\
\hline & $\Delta \tilde{S}_{H T}$ & $-0.2(11.7,0.71)$ & $-1.7(10.6,0.79)$ & $-2.7(10.2,0.78)$ & $-4.4(9.1,0.84)$ \\
\hline & $\Delta \tilde{S}_{U R N}$ & $-1.8(16.0,0.93)$ & $-4.1(15.6,0.94)$ & $-5.9(15.0,0.88)$ & $-8.2(14.6,0.84)$ \\
\hline & $\Delta \tilde{S}_{H W}$ & $-1.8(28.2,0.65)$ & $-12.5(23.8,0.69)$ & $-15.2(21.3,0.76)$ & $-11.1(19.3,0.92)$ \\
\hline
\end{tabular}


Table 7. Estimates of change in tree species richness in Minnesota (MN). RMSE and coverage of $95 \%$ confidence intervals are in parentheses (RMSE, coverage).

\begin{tabular}{|c|c|c|c|c|c|}
\hline$S_{2}-S_{1}$ & EST & $n=80$ & $n=150$ & $n=200$ & $n=300$ \\
\hline \multirow[t]{4}{*}{-2} & $\Delta \tilde{S}_{O}$ & $0.7(3.5,0.53)$ & $0.5(3.4,0.60)$ & $0.4(3.3,0.64)$ & $0.2(3.0,0.73)$ \\
\hline & $\Delta \tilde{S}_{H T}$ & $0.6(10.3,0.90)$ & $0.1(7.5,0.91)$ & $-0.3(6.9,0.91)$ & $-0.9(5.8,0.94)$ \\
\hline & $\Delta \tilde{S}_{U R N}$ & $1.1(14.7,0.92)$ & $-0.9(14.0,0.94)$ & $-1.4(13.3,0.94)$ & $-1.9(11.4,0.97)$ \\
\hline & $\Delta \tilde{S}_{H W}$ & $6.3(21.1,0.62)$ & $1.6(20.0,0.69)$ & $1.2(18.1,0.72)$ & $-4.8(16.6,0.73)$ \\
\hline \multirow[t]{4}{*}{-5} & $\Delta \tilde{S}_{O}$ & $0.6(6.0,0.12)$ & $0.3(5.7,0.20)$ & $0.0(5.5,0.21)$ & $-0.4(5.1,0.27)$ \\
\hline & $\Delta \tilde{S}_{H T}$ & $0.2(8.6,0.84)$ & $-0.6(8.3,0.87)$ & $-1.3(7.5,0.87)$ & $-2.4(6.2,0.92)$ \\
\hline & $\Delta \tilde{S}_{U R N}$ & $-0.1(15.0,0.95)$ & $-1.5(14.0,0.94)$ & $-3.5(13.8,0.95)$ & $-4.6(11.1,0.92)$ \\
\hline & $\Delta \tilde{S}_{H W}$ & $4.9(19.7,0.62)$ & $-0.9(19.6,0.66)$ & $-3.1(18.0,0.69)$ & $-8.0(16.0,0.75)$ \\
\hline \multirow[t]{4}{*}{-10} & $\Delta \tilde{S}_{O}$ & $0.41(10.6,0.00)$ & $0.0(10.3,0.00)$ & $-0.3(10.0,0.00)$ & $-0.8(9.4,0.01)$ \\
\hline & $\Delta \tilde{S}_{H T}$ & $-0.3(11.9,0.65)$ & $-1.4(11.1,0.68)$ & $-2.2(10.3,0.73)$ & $-3.6(8.6,0.75)$ \\
\hline & $\Delta \tilde{S}_{U R N}$ & $-1.2(17.0,0.92)$ & $-2.8(15.6,0.92)$ & $-4.8(14.2,0.91)$ & $-6.7(11.6,0.85)$ \\
\hline & $\Delta \tilde{S}_{H W}$ & $3.3(19.5,0.65)$ & $-2.8(19.4,0.65)$ & $-8.8(18.2,0.74)$ & $-8.5(15.9,0.67)$ \\
\hline
\end{tabular}

\section{Discussion and Conclusions}

Maintaining forest tree species diversity is an important imperative in the context of sustainable forestry (Castaňeda, Palmberg-Lerche, \& Vuorien, 2001; McDonald \& Lane, 2004; Mladenoff et al., 1993). Tracking the number of forest species and their abundance over time provides compelling information on the issue (Baffetta, Bacaro, Fattorini, Rocchini, \& Chiarucci, 2007; Chiarucci \& Bonini, 2005; Johnson, Mudrak, Beever, Sanders, \& Waller, 2008; Magnussen, et al., 2007). In the absence of exact knowledge about the status and trends 
in forest tree species diversity, the required information is typically derived from a forest resource inventory with repeat observations on a network of permanent sample locations (Corona et al., 2010; Winter, Chirici, McRoberts, Hauk, \& Tomppo, 2008). A professional identification of all encountered species is of paramount importance (Archaux, 2009; Archaux, et al., 2009).

It is known that the number of observed forest tree species in regional or national forest monitoring programs typically underestimates the actual number of forest species present in the sampled forests (Cao, et al., 2004; Chiarucci, et al., 2003; Gimaret-Carpentier, et al., 1998; Hellmann \& Fowler, 1999; Hwang \& Shen, 2010; Lam \& Kleinn, 2008; Magnussen \& Boudewyn, 2008). The exceptions are in forests with few relatively rare species and in the absence of rare forest tree species. A handful of model-based estimators of species richness at a given point in time - with an anticipated good performance in terms of bias and root mean squared errors - are now available (Magnussen, 2011; Magnussen, et al., 2010; Mingoti \& Meeden, 1992). The challenge of choosing the appropriate estimator for a given estimation problem, however, remains undiminished.

A design-unbiased estimator of change in species richness would be choice since it avoids reliance on a potentially biased model (Gregoire, 1998; Little, 2004). However, the results from this study suggest that the observed difference in species count between two repeated probability samples may exhibit more bias than a model-based estimator of change. Despite an attractive root mean squared error, the widespread failure of computed confidence intervals to include the actual change in species richness stands as a serious detractor for using the observed difference as the estimator of change. This failure is not caused by a poor estimator of the sampling variance of the observed species count (Magnussen, 2009; Magnussen \& McRoberts, 2011). Further studies are clearly needed to confirm whether performance of the direct estimate of change reported here is general or not.

When a decision is made to use a model-based estimator of species richness and change in species richness between repeated sampling events, the question of which estimator to use emerges. For the purpose of estimating forest tree species richness - at a given point in time from a sample of species incidence data collected from fixed-area survey plots, the estimators by Shen and He (2008), Mingoti and Meeden (1992), Magnussen et al. (2010), and Magnussen (2011) hold promise. Although any estimator of species richness can be used for estimation of change from repeat sample-based observation of species incidence data, the efficiency of the chosen estimator, in terms of variance, depends on how well it captures the temporal correlation of species incidence. As demonstrated, both the HT and the URN estimators of species richness can be modified to deal with longitudinal data. Although the bootstrap resampling scheme is designed to capture temporal correlations, this study indicated that it is less efficient in doing so than either HT or URN. The temporal correlation between $\tilde{S}_{H W 2}$ and $\tilde{S}_{H W 1}$ was lower (mean difference of approximately 0.3 ) than the temporal correlation between $\tilde{S}_{H T 2}$ and $\tilde{S}_{H T 1}$ and also lower than the correlation 
between $\tilde{S}_{U R N 2}$ and $\tilde{S}_{U R N 1}$. With the URN estimator of change the estimates of the temporal correlation were nearly as strong as the correlation between the observed sample-based species counts (mean of approximately 0.8 ). The direct use of longitudinal incidence records in the urn model is considered a likely explanation for this result.

For estimation of change in species richness the URN estimator emerged as more attractive overall than its competitors $\left(\Delta \mathrm{SO}, \Delta S_{H T}, \Delta S_{H W}\right)$ in terms of bias (it ranked first 22 times out of 48) and coverage of computed confidence interval (best coverage 28 times out of 48). None of the other estimators, $\Delta \mathrm{SO}, \Delta S_{H T}$ and $\Delta S_{H W}$, came close to this performance.

\section{Acknowledgements}

Data from the US Forest Service Forest Inventory Programme (GA, MI, MN) were kindly made available by Dr. Brad Smith, Wash. DC. Patrick Miles (USDA Forest Service Northern Research Station) helped organize the data. The BCI forest dynamics research project was made possible by National Science Foundation grants to Stephen P. Hubbell: DEB-0640386, DEB-0425651,DEB-0346488, DEB-0129874, DEB-00753102， DEB-9909347, DEB-9615226, DEB-9615226, DEB-9405933, DEB-9221033, DEB-9100058, DEB-8906869, DEB-8605042,DEB-8206992, DEB-7922197, support from the Center for Tropical Forest Science, the Smithsonian Tropical Research Institute, the John D. and Catherine T. MacArthur Foundation, the Mellon Foundation, the Celera Foundation, and numerous private individuals, and through the hard work of over 100 people from 10 countries over the past two decades. The plot project is part of the Center for Tropical Forest Science, a global network of large-scale demographic tree plots.

\section{References}

Archaux, F. (2009). Could we obtain better estimates of plot species richness from multiple-observer plant censuses? Journal of Vegetation Science, 20(4), 603-611

Archaux, F., Camaret, S., Dupouey, J. L., Ulrich, E., Corcket, E., Bourjot, L., . . . Touffet, J. (2009). Can we reliably estimate species richness with large plots? an assessment through calibration training. Plant Ecology, 203(2), 303-315

Baffetta, F., Bacaro, G., Fattorini, L., Rocchini, D., \& Chiarucci, A. (2007). Multi-stage cluster sampling for estimating average species richness at different spatial grains. Community Ecology, 8(1), 119-127

Bechtold, W. A., \& Patterson, P. L. (2005). The enhanced forest inventory and analysis program - National sampling design and estimation procedures (U. F. Service, Trans.) (pp. 85). Asheville, NC

Brose, U., Martinez, N. D., \& Williams, R. J. (2003). Estimating species richness: Sensitivity to sample coverage and insensitivity to spatial patterns. Ecology, 84(9), 2364-2377 
Cao, Y., Larsen, D. P., \& White, D. (2004). Estimating regional species richness using a limited number of survey units. Ecoscience, 11(1), 23-35

Castaňeda, F., Palmberg-Lerche, C., \& Vuorien, P. (2001). Criteria and indicators of sustainable forest management: A compendium Forest Management Working Paper. Rome: Food and Agriculture Organization of the United Nations (FAO)

Chiarucci, A., \& Bonini, I. (2005). Quantitative floristics as a tool for the assessment of plant diversity in Tuscan forests. Forest Ecology and Management, 212(1-3), 160-170

Chiarucci, A., Enright, N. J., Perry, G. L. W., \& Miller, B. P. (2003). Peformance of nonparametric species richness estimators in a high dieversity plant community. Diversity and Distributions, 9, 283-295

Chong, G. W., Reich, R. M., Kalkhan, M. A., \& Stohlgren, T. J. (2001). New approaches for sampling and modeling native and exotic plant species richness. Western North American Naturalist, 61(3), 328-335

Condit, R., Foster, R. B., Hubbell, S. P., Sukumar, R., Leigh, E. G., Manokaran, N., . . . Comiskey, J. (1998). Assessing forest diversity from small plots: calibration using species-individual curves from 50 ha plots. In F. Dallmeier \& J. A. Comiskey (Eds.), Forest biodiversity research, monitoring and modeling: Conceptual background and old world case studies (pp. 247-268). Paris: Parthenon

Condit, R., \& Hubbell, S. P. (1998). Tropical Forest Census Plots: Methods and Results from Barro Colorado Island, Panama and a Comparison with Other Plots. Berlin: Springer

Condit, R., Hubbell, S. P., \& Foster, J. R. (1996). Changes in tree species abundance in a neotropical forest: Impact of climate change. Journal of Tropical Ecology, 12, 231-256

Corona, P., Blasi, C., Chirici, G., Facioni, L., Fattorini, L., \& Ferrari, B. (2010). Monitoring and assessing old-growth forest stands by plot sampling. Plant Biosystems, 144(1), 171-179

Efron, B., \& Tibshirani, R. J. (1993). An introduction to the bootstrap. Boca Raton: Chapman \& Hall

Fewster, R. M., \& Buckland, S. T. (2001). Similarity Indices for Spatial Ecological Data. Biometrics, 57(2), 495-501 doi: doi:10.1111/j.0006-341X.2001.00495.x

Foster, J. R. (2001). Statistical power in forest monitoring. Forest Ecology and Management, $151,211-222$

Gavin, D. G., Beckage, B., \& Osborne, B. (2008). Forest dynamics and the growth decline of red spruce and sugar maple on Bolton Mountain, Vermont: a comparison of modeling methods. Canadian Journal of Forest Research, 38(10), 2635-2649

Gimaret-Carpentier, C., Pelissier, R., Pascal, J. P., \& Houllier, F. (1998). Sampling strategies for the assessment of tree species diversity. Journal of Vegetation Science, 9(2), 161-172

Gregoire, T. G. (1998). Design-based and model-based inference in survey sampling: 
appreciating the difference. Canadian Journal of Forest Research, 28, 1429-1447

Halpern, C. B., \& Spies, T. A. (1995). Plant species diversity in natural and managed forests of the Pacific Northwest. Ecological Applications, 5, 913-934

He, F., \& Hubbell, S. P. (2003). Percolation theory for the distribution and abundance of species. Physical Review Letters, 91(19), 4

He, H. S., Mladenoff, D. J., \& Gustafson, E. J. (2002). Study of landscape change under forest harvesting and climate warming-induced fire disturbance. Forest Ecology and Management, 155, 257-270

Hellmann, J. J., \& Fowler, G. W. (1999). Bias, precision, and accuracy of four measures of species richness. Ecological Applications, 9(3), 824-834

Hortal, J., Borges, P. A. V., \& Gaspar, C. (2006). Evaluating the performance of species richness estimators: sensitivity to sample grain size. Journal of Animal Ecology, 75(1), 274-287

Hubbell, S. P., Foster, R. B., O'Brien, S. T., Harms, K. E., Condit, R., Wechsler, B., . . Lao., S. L. d. (1999). Light gap disturbances, recruitment limitation, and tree diversity in a neotropical forest. Science, 283, 554-557

Hwang, W.-H., \& Shen, T.-J. (2010). Small-Sample Estimation of Species Richness Applied to Forest Communities. Biometrics, 66(4), 1052-1060

Jaccard, P. (1901). Étude comparative de la distribution florale dans une portion des Alpes et des Jura. Bulletin de la Société Vaudoise des Sciences Naturelles, 37, 547-579

Johnson, S. E., Mudrak, E. L., Beever, E. A., Sanders, S., \& Waller, D. M. (2008). Comparing power among three sampling methods for monitoring forest vegetation. [Article]. Canadian Journal of Forest Research, 38(1), 143-156

Kienast, F., Brzeziecki, B., \& Wildi, O. (1996). Long-term adaptation potential of Central European mountain forests to climate change: a GIS-assisted sensitivity assessment. Forest Ecology and Management, 80, 133-153

Lam, T. Y., \& Kleinn, C. (2008). Estimation of tree species richness from large area forest inventory data: Evaluation and comparison of jackknife estimators. Forest Ecology and Management, 255, 1002-10010

Lister, A., \& Scott, C. (2009). Use of space-filling curves to select sample locations in natural resource monitoring studies. Environmental Monitoring and Assessment, 149(1), 71-80

Little, R. J. A. (2004). To model or not to model? Competing modes of inference for finite population sampling. Journal of the American Statistical Association, 99 (466), 546-556

Lophaven, S., Carstensen, J., \& Rootzen, H. (2004). Space-time modeling of environmental monitoring data. Environmental and Ecological Statistics, 11(3), 237-256

Magnussen, S. (2009). A balanced repeated replication estimator of sampling variance for 
apparent and predicted species richness. Forest Science, 55(3), 189-200

Magnussen, S. (2011). A Horvitz-Thompson type estimator of species richness. Envirometrics doi: $10.1002 /$ env.1117

Magnussen, S., \& Boudewyn, P. (2008). Estimators of tree species richness: An assessment for Central and Eastern Canada. Journal of Sustainable Forestry, 26(1), 77-96

Magnussen, S., \& McRoberts, R. (2011). A modified bootstrap procedure for cluster sampling variance estimation of species richness. Journal of Applied Statistics (in press)

Magnussen, S., Péllisier, R., He, F., \& Ramesh, B. R. (2006). An assessment of sample-based estimators of tree species richness in two wet tropical forest compartments in Panama and India. International Forestry Review, 8(4), 417-431

Magnussen, S., Smith, B., Kleinn, C., \& Sun, I. F. (2010). An urn model for species richness estimation in quadrat sampling from fixed-area populations. Forestry, 83(3), 293-306

Magnussen, S., Smith, B., \& Uribe, A. S. (2007). National Forest Inventories in North America for monitoring forest species diversity. Plant Biosystems, 141(1), 113-122

Mao, C. X., \& Lindsay, B. G. (2007). Estimating the Number of Classes. Annals of Statistics, $35,917-930$

Martin, C. W., \& Bailey, A. S. (1999). Twenty years of change in a northern hardwood forest. Forest Ecology and Management, 123(2-3), 253-260

McDonald, G. T., \& Lane, M. B. (2004). Converging global indicators for sustainable forest management. Forest Policy and Economics, 6(1), 63-70

Mingoti, S. A., \& Meeden, G. (1992). Estimating the total number of distinct species using presence and absence data. Biometrics, 48(3), 863-875

Mladenoff, D. J., Pastor, W. J., Aplet, G. H., Olson, J. T., Johnson, N., \& Sample, V. A. (1993). Sustainable forst ecosystems in northern hardwood and conifer region: Concepts and management Defining sustainable forestry. (pp. 145-180). Washington DC: Island Press

Purvis, A., \& Hector, A. (2000). Getting the measure of biodiversity. Nature, 405, 212-219

Radeloff, V. C., Mladenoff, D. J., He, H. S., \& Boyce, M. S. (1999). Forest landscape change in the northwestern Wisconsin Pine Barrens from pre-European settlement to the present. Canadian Journal of Forest Research, 29(11), 1649-1659

Sarkar, S., \& Margules, C. (2002). Operationalizing biodiversity for conservation planning. Journal of Biosciences, 27(4), 299-308

Shen, T. J., \& He, F. L. (2008). An incidence-based richness estimator for quadrats sampled without replacement. Ecology, 89(7), 2052-2060

Sørensen, T. (1957). A method of establishing groups of equal amplitude in plant sociology based on similarity of species and its application to analyses of the vegetation on Danish 


\section{Macrothink}

Journal of Environment and Ecology

ISSN 2157-6092

2011, Vol. 2, No. 1: E1

commons Biologiske Skrifter (Vol. 5, pp. 34). Copenhagen, DK: Kongelige Videnskabernes Selskab

Spencer, R. D., \& Czaplewski, R. L. (1998). National forest inventory in the USA: An outline of the procedure. Australian Forestry, 60(1), 56-66

Swindel, B. F., Conde, L. F., \& Smith, J. E. (1984). Species diversity: concept measurement, and response to clearcutting and site preparation. Forest Ecology and Management, 8, 11-22

Thompson, S. K. (1992). Sampling. New York: Wiley

Waldhardt, R., Simmering, D., \& Otte, A. (2004). Estimation and prediction of plant species richness in a mosaic landscape. Landscape Ecology, 19(2), 211-226

Walther, B. A., \& Morand, S. (1998). Comparative performance of species richness estimation methods. Parasitology, 116, 395-405

Wei, S., Li, L., Walther, B. A., Ye, W., Huang, Z., Cao, H., . . Chen, Y. (2010). Comparative performance of species-richness estimators using data from a subtropical forest tree community. Ecological Research, 25(1), 93-101

Winter, S., Chirici, G., McRoberts, R. E., Hauk, E., \& Tomppo, E. (2008). Possibilities for harmonizing national forest inventory data for use in forest biodiversity assessments. [Article]. Forestry, 81(1), 33-44

Yasuhiro, K., Hirofumi, M., \& Kihachiro, K. (2004). Effects of topographic heterogeneity on tree species richness and stand dynamics in a subtropical forest in Okinawa Island, southern Japan. Journal of Ecology, 92(2), 230-240 